\title{
Tadalafil-loaded PLGA microspheres for pulmonary administration: preparation and evaluation
}

\author{
Zhenlei Yang ${ }^{1}$, Longmei Wang ${ }^{\circledR 1}$, Liu Tian¹, Xiuping Zhang ${ }^{1}$, Guihua Huang1* \\ ${ }^{1}$ School of Pharmaceutical Sciences, Shandong University, Ji'nan, China
}

\begin{abstract}
Tadalafil, a long-acting PED-5 inhibitor, is commonly used for the treatment of pulmonary arterial hypertension (PAH). However, its efficacy and clinical application are severely limited by the poor water solubility, low bioavailability and a series adverse effects (e.g. headaches, indigestion). In this study, tadalafil was prepared and loaded into biodegradable PLGA (poly(lactic-co-glycolic acid)) microspheres (TDF-PLGA-MS) via emulsification-solvent evaporation. The resulting microspheres were processed into pulmonary inhalant by freeze drying. The TDF-PLGA-MS was spherical and uniform, with an average particle diameter $\sim 10.29 \mu \mathrm{m}$. The encapsulation efficiency and drug loading yield of TDF-PLGA-MS were $81.68 \%$ and $8.52 \%$, respectively. The investigation of micromeritics showed that the TDF-PLGA-MS had low moisture content. The fluidity of powders was relatively good. The aerodynamic diameter and emptying rate of microspheres powders were $3.92 \mu \mathrm{m}$ and $95.41 \%$, respectively. Therefore, the microspheres powders were easy to be atomized, and can meet the requirements of pulmonary administration. In vitro release results showed that the microspheres group released slowly. The cumulative release in $24 \mathrm{~h}$ and $10 \mathrm{~d}$ was $46.87 \%$ and $84.06 \%$, respectively. The in vitro release profile of TDF-PLGA-MS was in accordance with the Weibull model. The results of Pharmacokinetics showed that tadalafil from microspheres slowly released into the blood after intratracheal instillation. The pulmonary drug residue in $0.5 \mathrm{~h}$ was 3.5 times compared with solution group. The residual concentration in lung after 10d was still higher than that of solution group in $48 \mathrm{~h}$. The $\mathrm{t}_{1 / 2} \beta$ and $\mathrm{MRT}_{0-\infty}$ were 3.10 times and 3.96 times that of solution group, respectively. Moreover, the $\mathrm{C}_{\max }$ and $\mathrm{AUC}$ of drug residues in lung were 3.48 times and 16.36 times that of solution group, respectively. The results of tissue distribution showed that the Re in lung was 16.358, which indicated the lung targeting. In conclusion, the TDF-PLGA-MS for pulmonary administration in this study can significantly improve the pulmonary targeting, increase efficacy of tadalafil and reduce other non-target organs toxicity. This study will have an important clinical significance for PAH patients who need long-term drug therapy.
\end{abstract}

Keywords: Pulmonary arterial hypertension. Tadalafil. PLGA. Microspheres. Pulmonary administration. Micromeritic. In vitro release. Pharmacokinetic. Tissue distribution.

\section{INTRODUCTION}

Pulmonary arterial hypertension (PAH) is a pulmonary vascular disease caused by different etiological factors. The clinical manifestations of PAH include persistently elevated pulmonary artery pressure, which subsequently lead to right ventricular hypertrophy, right heart failure and even death (Chin, Rubin, 2008). Generally, one person with average pulmonary artery pressure in left ventricular catheter $\geq 25 \mathrm{~mm} \mathrm{Hg}$ at rest will

\footnotetext{
*Correpondence: G. Huang. School of Pharmaceutical Sciences, Shandong University, 44 Wenhua west Road, Ji'nan, 250012, China. Tel: (086)053188382015, Fax: (086)0531-88382548. E-mail: hgh2003@gmail.com. Zhenlei Yang and Longmei Wang equally contribute to this research.
}

be diagnosed with PAH (Hoeper et al., 2014; Barst et al., 2004). PAH is a highly malignant disease with poor prognosis and high mortality (Fenstad et al., 2013). The traditional drugs for PAH include anticoagulants, cardiotonics, diuretics etc. whose therapeutic mechanism is mainly reducing pulmonary artery pressure. Although these treatments can relieve and improve clinical symptoms of PAH patients, they still cannot delay the worsening of PAH. With the deepening research on pathogenesis of PAH, new targeted drugs for PAH constantly emerge to extend the survival time. The classic novel targeted drugs for PAH include prostacyclin and its analogs, endothelin receptor antagonist, phosphodiesterase type-5 (PDE-5) inhibitors, 
etc (Galiè et al., 2015; Gomberg, Olschewski, 2008; Rhodes et al., 2009; Archer, Michelakis, 2009).

Tadalafil (TDF), a long-term PED-5 inhibitor, is originally used to treat male erectile dysfunction, with therapeutic dose of $10 \mathrm{mg} / \mathrm{d}$. It is approved for the treatment of PAH by the U.S. Food and Drug Administration in May 2009. The corresponding therapeutic dose is $40 \mathrm{mg} / \mathrm{d}$. TDF can significantly increase exercise tolerance in patients with PAH, improved flow-mediated vessel dilation and delay further deterioration of PAH without dietary effect (Oudiz et al., 2012; Galiè et al., 2009; Kloner, Mitchell, Emmick, 2003). Long-term TDF treatments are generally essential for PAH patients, during which obvious adverse reactions are observed including headache, indigestion, nasal congestion, etc (Carson et al., 2004). Further, the poor water solubility results in low bioavailability of TDF. So new dosage form of TDF is needed to improve the bioavailability and reduce side effects of long-term treatments, which have important clinical significance for the treatments of PAH.

At present, sustained release microspheres for inhalation made from biodegradable polymer material, combining advantages of local targeting administration with sustained release formulations have been paid great attention. First, drugs are delivered to the lesion directly by local targeted administration, which can reduce the dosage and systemic adverse reactions (Azarmi, Roa, Löbenberg, 2008). Second, sustained release preparation can prolong the duration of action. The drug concentration is maintained at a therapeutically effective concentration or more, reducing the frequency of administration, improving the therapeutic effect (Zeng, Martin, Marriott, 1995; Hardy, Chadwick, 2000). Biodegradable materials commonly used include starch, chitosan, polylactic acid (PLA), poly (lactic-co-glycolic acid) (PLGA), etc (Freiberg, Zhu, 2004). Currently, PLGA with good biocompatibility and biodegradability has been one of the most commonly used biodegradable materials. PLGA is cleaved into a hydroxy acid and lactic acid in vivo. Subsequently, the resultants are transformed into carbon dioxide and water (Anderson, Shive, 2012). So no hazardous substance accumulates in the body. In addition, different release rate can be achieved by changing the ratio of lactic acid to glycolic acid (Park, 1995). Collectively, PLGA microspheres for pulmonary administration have the following advantages: (1) Both convenient usage and decreasing frequency of administration can increase patient compliance (Cook, Pannu, Kellaway, 2005); (2) The steady plasma concentration of drug within effective range can reduce side effects caused by rapid release of drug, which makes it possible to achieve a high security;
(3) Drugs are directly delivered to the lesion to achieve a better therapeutic effect without hepatic first-pass effect; (4) The PLGA microspheres made from biodegradable material have a good biocompatibility; (5) The particle size is controllable, so the size of PLGA microspheres suitable for pulmonary administration can be achieved through optimization of technology and prescription; microspheres less than $1.4 \mu \mathrm{m}$ are usually all through the pulmonary circulation, 7-14 $\mu \mathrm{m}$ microspheres mainly stay in the lungs, and the microspheres less than $3 \mu \mathrm{m}$ remain in the liver and spleen mostly (Carvalho, Peters, Williams, 2011). (6) The retention time of drugs in the lung can be greatly prolonged, so the drugs can be slowly released (Dunne, Corrigan, Ramtoola, 2000).

The gold therapy for respiratory diseases is inhaled route of administration which is widely used for lung diseases (Sham et al., 2004; Ely et al., 2007; Kleinstreuer, Zhang, Donohue, 2008). Currently, the main pulmonary inhalation formulations include metered dose inhaler, atomization inhalant and dry powder inhalant. Compared with several other inhalants, powder inhalant is administrated by active inhalation. So there are no difficulties in synchronization between manual trigger and breathing (Watts, McConville, Williams, 2008). In this study, single-dose dry powder inhaler like Spinhaler and Rotahaler will be used for pulmonary administration. This paper aims to prepare tadalafil loaded PLGA microspheres for pulmonary inhalation. Subsequently, the physicochemical properties, micromeritic properties and release characteristic in vitro are studied and evaluated respectively. Tadalafil solution as the control group, pharmacokinetics and tissue distribution in Wistar rat are studied and evaluated after intratracheal instillation of tadalafil PLGA microspheres suspensions to explore the long-term sustained release characteristic and safety. This formulation can not only control the release of drugs but reduce systemic toxicity, which are be conducive to improving the therapeutic effect.

\section{MATERIAL AND METHODS}

\section{Material}

Tadalafil was provided by Qilu Pharmaceutical Co., Ltd. PLGA (50:50, $\left.\mathrm{M}_{\mathrm{w}}=15000-25000\right)$ was purchased from Advanced Polymer Materials Inc. (Montreal, Canada). PVA (Alcoholysis degree: 87-89\%) was obtained from the Sigma USA. Methylene chloride (99.9\% HPLC grade) was purchased from Fu Yu Fine Chemical Co., Ltd, Tianjin, China. Acetone (analytical grade) was purchased from Laiyang Fine Chemical Plant, Laiyang, China. The other chemicals were of analytical reagent grade or higher. 


\section{Methods}

\section{Preparation of TDF-PLGA-MS}

Tadalafil loaded microspheres were prepared by modified emulsion-solvent evaporation method. The lipid phase and aqueous phase were prepared respectively. $5 \mathrm{mg}$ of tadalafil and $30 \mathrm{mg}$ of PLGA were weighted precisely and co-dissolved in $0.3 \mathrm{~mL}$ of acetone-methylene chloride (0.1:0.2) mixed solvent as lipid phase. In addition, $1.2 \mathrm{~mL}$ of $5 \%(\mathrm{w} / \mathrm{v})$ PVA solution was as aqueous phase. Then, the lipid phase was added into the aqueous phase dropwise and stirred ( $5000 \mathrm{rpm}, 0.5 \mathrm{~min}$ ) to form a primary emulsion by tissue tearor. The primary emulsion was poured into $18 \mathrm{~mL}$ of $2 \%$ PVA solution (dispersed phase) and stirred for $3 \mathrm{~h}$ at $25{ }^{\circ} \mathrm{C}$. The PLGA microspheres were obtained when organic solvents were removed by evaporation.

\section{Optimization of formulation with orthogonal experimental design}

Based on the investigation of single factor, four factors greatly affecting entrapment efficiency were chosen as research objects. They were (A) the ratio of drug to PLGA (w/w), (B) the concentration of PLGA (w/v), (C) the volume ratio of lipid to aqueous phase, (D) the volume ratio of aqueous to dispersed phase, respectively. Nine formulations were designed according to $\mathrm{L}_{9}\left(3^{4}\right)$ orthogonal design to screen the optimal formulation and process. With encapsulation efficiency as evaluation index, the factors and levels of the orthogonal design were listed in Table I.

TABLE I - Factors and levels of the orthogonal experimental design

\begin{tabular}{lcccc}
\hline \multirow{2}{*}{ Levels } & \multicolumn{4}{c}{ Factors } \\
\cline { 2 - 5 } & $\mathbf{A}(\mathbf{W} / \mathbf{W})$ & $\mathbf{B}(\mathbf{m g} / \mathbf{m L})$ & $\mathbf{C}(\mathbf{V} / \mathbf{V})$ & $\mathbf{D}(\mathbf{V} / \mathbf{V})$ \\
\hline 1 & $1: 6$ & 60 & $1: 2$ & $1: 5$ \\
2 & $1: 8$ & 80 & $1: 4$ & $1: 10$ \\
3 & $1: 10$ & 100 & $1: 6$ & $1: 15$ \\
\hline
\end{tabular}

Footer: A, B, C, D were (A) the ratio of drug to PLGA (w/w), (B) the concentration of PLGA (w/v), (C) the volume ratio of oil phase to aqueous phase, (D) the volume ratio of aqueous to dispersed phase, respectively.

\section{Freeze-drying of TDF-PLGA-MS}

In the freeze-drying process, mannitol $(2 \%, \mathrm{w} / \mathrm{v})$ was used as a cryoprotectant. First of all, $1 \mathrm{~mL}$ of freshly prepared TDF-PLGA-MS suspension (contain $5 \mathrm{mg}$ of tadalafil) were washed with distilled water three times and mixed with mannitol. Subsequently, the mixture were pre-frozen using an ultra-cold freezer (MDF-382E, Sanyo Electric Co., Ltd., Osaka, Japan) at $-80^{\circ} \mathrm{C}$ for $12 \mathrm{~h}$. Then, the resultant samples were transferred to the lyophilizer (Alpha 1-2 LD, Christ, Germany) at $-45^{\circ} \mathrm{C}$ for $24 \mathrm{~h}$. The lyophilized powder was collected for further experiments.

\section{Characterization of TDF-PLGA-MS}

\section{Physical and chemical property}

The morphology of TDF-PLGA-MS was examined using optical microscope (OM, Alphaphot-2 YS2, Nikon, Japan). Moreover, the powder samples of TDF-PLGA-MS were fixed on the spindle with double-sided adhesive. Then, the samples were plated under argon protection. Finally, the surface of the microspheres was observed under scanning electron microscopy (SEM, JSM-840A, Jeol, Tokyo, Japan) after the gold plating. The size distribution of the PLGA microspheres was determined using laser particle size analyzer (Mastersize 2000, Malvern, Britain). The $\mathrm{pH}$ value of TDF-PLGA-MS suspensions was determined using $\mathrm{pH}$ meter (FiveEasy, Mettler Toledo, Switzerland). The blank MS was prepared in the same process with drug-loaded TDF-PLGA-MS. Then, PLGA, TDF, physical mixture and TDF-PLGA-MS were characterized by DSC measurements (DSC822e, Mettler Toledo, Switzerland). These characterizations were used to examine the physical and chemical stability of the drug-loaded microspheres.

\section{Determination of encapsulation efficiency (EE) and drug loading $(D L)$}

The EE and DL of TDF-PLGA-MS were determined by ultraviolet spectrophotometry (TU-1810, Puxi, Beijing, China). Firstly, TDF-PLGA-MS suspension was centrifuged at $8000 \mathrm{rpm}$ for $10 \mathrm{~min}$. After discarding the supernatant, the precipitate was washed three times with distilled water. 13 mg precipitate was precisely weighed, dissolved in dimethyl sulfoxide-acetonitrile (1: 1) in volumetric flask $(10 \mathrm{~mL})$ and diluted to volume. The absorbance was measured at 285 $\mathrm{nm}$. The EE and DL were calculated in accordance with the formula (1) and (2), respectively.

$$
\begin{array}{r}
\mathrm{EE}(\%)=\frac{W_{\text {practice }}}{W_{\text {theory }}} \times 100 \% \\
\mathrm{DL}(\%)=\frac{W_{\text {practice }}}{W_{P L G A}} \times 100 \%
\end{array}
$$

where $\mathrm{W}_{\text {theory }}, \mathrm{W}_{\text {practice }}$ and $\mathrm{W}_{\text {PLGA }}$ are the weight of drug added, the weight of TDF in microspheres and the weight of PLGA added in system, respectively. 


\section{Micromeritic}

\section{Moisture content}

The moisture content of dried powder has a great impact on atomization process: with the increase of moisture content, the powder is easy to assemble and hard to disperse. Therefore, it is hard to be atomized and emptied, resulting in a decrease of deposition on lesions (Lakio et al., 2015). So the moisture content of the powder has great influence on pulmonary administration. In this paper, we determined the moisture content using KarlFisher Titrator (YT-11133F, Shanghai yutong instrument Factory). $0.5 \mathrm{~g}$ dried powder of microspheres was weighed precisely and placed in the titrator. Then, the moisture content was calculated after titration.

\section{Bulk density}

The bulk density is equal to the ratio of mass to volume of powder, indicating the bulkiness degree of powder (Lam et al., 2014). The smaller the bulk density is, the fluffier the powder is. So it is easier to disperse into fine particles and reach the lung. To some extent, this is good for reducing the residues in the respiratory tract. In this research, the bulk density of microspheres powder was measured by measuring cylinder method. $5.0 \mathrm{~g}$ of tadalafil microspheres powder was weighed precisely and placed into the measuring cylinder $(10 \mathrm{~mL})$. At $5 \mathrm{~cm}$ away from the desktop, the measuring cylinder free fell vertically for three times. Then the volume of powder was recorded. The bulk density was calculated according to following equation.

$$
\rho=\mathrm{W} / \mathrm{V}
$$

where $\rho, \mathrm{W}$ and $\mathrm{V}$ are the bulk density, mass and volume of powder, respectively.

\section{Repose angle}

With easy operation, low cost and good reproducibility, the angle of repose of powder is commonly used to indicate flowability of powder (Wong, 2002). We measured the angle of repose of the microspheres powder using the funnel method. The funnel was fixed at a specified height above the right origin of a disc, a certain amount of microspheres powder fell freely from the funnel until a cone with certain radius (about $5 \mathrm{~cm}$ ) was formed. Then the height of cone was determined and the angle of repose was calculated according to following equation.

$$
\tan \theta=\mathrm{H} / \mathrm{r}
$$

where $\theta, \mathrm{H}$ and $\mathrm{r}$ are the angle of repose, height and radius of cone, respectively. Moreover, the angle of repose of less than 30 degrees indicates the powder flowability was good. When the angle of repose was less than 40 degrees, it is able to meet the production requirements for flowability.

\section{Aaerodynamic equivalent diameter}

Due to different density and shape, powders with the same size of different materials have different settling velocity in the air, so the sedimentation site in respiratory tract is also different. In order to compare with each other, the concept of aerodynamic diameter is proposed. W. Stober defined the aerodynamic diameter of actual particle as the diameter of the spherical particle with a density of $1 \mathrm{~g} / \mathrm{cm}^{3}$ and the same settling velocity as the actual particle. Compared with actual particle size, the aerodynamic diameter can properly describe the dynamic characteristics of pulmonary inhalation. The aerodynamic diameter is together determined by the geometric size and tapped density of particles (Salma et al., 2015). We calculated the aerodynamic diameter according to the following empirical formula of aerodynamic diameter (d') estimated theoretical value (Wang, John, 1987).

$$
\mathrm{d}^{\prime}=\sqrt{1.26 \rho / \rho 1} \times \mathrm{d}
$$

where $\rho$ is the tapped density of TDF-PLGA-MS powders without mannitol, $\rho 1=1 \mathrm{~g} / \mathrm{cm} 3$, $d$ is the average geometric diameter of particles.

\section{Atomization characteristics}

Refering to relevant literatures and Chinese Pharmacopoeia (2010 edition), volume II, Appendix X, we made the atomization device to measure the uniform degree of smog after atomization. The experimental apparatus is shown in Figure 1. A certain amount of microspheres powder was weighed and filled into No. 3 capsule. Subsequently, the capsule was placed into the inhalation device after perforation. Then the inhalation device was connected with a $5000 \mathrm{~mL}$ glass bottle via valve. At the moment, the valve was closed. The glass bottle was vacuumized at the flow rate of $60 \mathrm{~L} / \mathrm{min}$. After switching on the valve, microspheres powder was ejected from inhalation device. The same operation was repeated for four times, and the duration was $1.5 \mathrm{~s}$ for each time. If powder formed uniform smog after ejection and no large particles were found after deposition, which indicated a very easy atomization. This moment, the atomization level was " 3 ". If most of the powder formed uniform smog, only a small amount of large particles were found on the bottom, which indicated an easy atomization. At the same 
time, the atomization level was " 2 ". If most of the powder formed large particles and deposited on the bottom, which indicated a atomization. At the moment, the atomization level was "1".

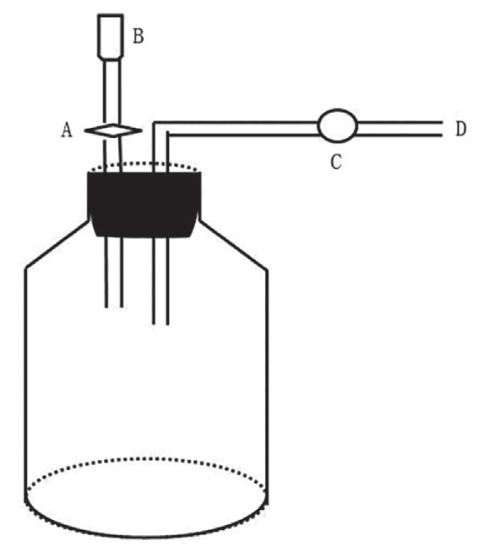

FIGURE 1 - Experimental devices of emptying rate and atomization determination A:Valve; B:Inhaler; C:Vacuum indicator; D:Vacuum pump.

\section{Emptying rate}

The same operation was repeated according to "2.2.5.5". A certain amount of microspheres powder was weighed precisely and filled into empty capsule. At the same time, the mass of empty capsule before and after use was precisely weighed as well. Emptying rate (ER) was calculated according to the following formula.

$$
\mathrm{ER}=[(\mathrm{w} 1-\mathrm{w} 2) /(\mathrm{w} 1-\mathrm{w} 3)] \times 100 \%
$$

where w1, w2 and w3 were the mass of microspheres powder filled into capsule, empty capsule before and after use, respectively.

\section{The drug release experiment in vitro}

The release experiment in vitro was performed using dynamic dialysis method. The right amount of microspheres powder (about containing tadalafil $448 \mu \mathrm{g}$, equivalent to the same amount of tadalafil solution) was precisely weighed and suspended in $1 \mathrm{~mL}$ phosphate buffer (pH7.4, containing 2\% Tween-80 and $0.3 \%$ NaN3). The resultant suspension was placed in dialysis bags with 8 14 kDa molecular weight cut-off. The dialysis bags were incubated in $10 \mathrm{~mL}$ of phosphate buffer ( $\mathrm{pH} 7.4$, containing $2 \%$ Tween- 80 and $0.3 \% \mathrm{NaN} 3$ ) which was filled in well-closed tubes as dissolution medium. The tubes were placed in a constant temperature water bath oscillator with $100 \mathrm{rpm}$ at $37 \pm 1{ }^{\circ} \mathrm{C}$. An appropriate amount of tadalafil was weighed and dissolved in dimethyl sulfoxide-acetonitrile (1:1). Then, the resultant solution was diluted with dissolution medium. Finally, the tadalafil solution with a concentration of $448 \mu \mathrm{g} / \mathrm{mL}$ was obtained. With $1 \mathrm{~mL}$ tadalafil solution ( $448 \mu \mathrm{g} / \mathrm{mL})$ as control group, $4 \mathrm{~mL}$ dispersion sample was withdrawn at scheduled time intervals $(0.5,1,2,4,6,8,12,24,48,72,96,120,144$, 198 and $240 \mathrm{~h}$ ) and its drug content was determined at $285 \mathrm{~nm}$ by UV method as described above. Equal volume of fresh dissolution medium was added into the tubes to maintain the constant volume. This drug-release assay was performed in triplicate. The cumulative release percentage was calculated to draw in vitro release profile.

Furthermore, we applied Zero-order model, First-order model, Higuchi model, Weibull model, Ritger-Peppas model to fit the release data, respectively. Moreover, r was used to choose the optimal release model. The larger the r value was, the closer the model was to the true model.

\section{Animals}

Wistar rats (weighted between $160 \sim 200 \mathrm{~g}$, provided by the Medical Animal Test Center of Shandong University) were used for the study of Pharmacokinetics and tissue distribution. The animals were fasted for $12 \mathrm{~h}$ before drug administration. The animal experiment protocol was reviewed and approved by the Institutional Animal Care and Use Committee of Shandong University.

\section{Pharmacokinetics and tissue distribution studies in rats}

Six healthy wistar rats were randomLy divided into two groups. Control group was treated with tadalafil solution by intratracheal instillation while study group was treated with TDF-PLGA-MS suspension. The tadalafil doses were all $10 \mathrm{mg} / \mathrm{kg}$. Blood samples were taken from the neck sinus at scheduled time points $(0.5,1,2,4,6,8$, $12,24,36$ and $48 \mathrm{~h}$ ) and placed into micro-tubes containing sodium heparin as anticoagulant. $0.3 \mathrm{~mL}$ of acetonitrile was added to an aliquot $(0.2 \mathrm{~mL})$ of each plasma sample and mixed for $4 \mathrm{~min}$ by vortex to extract tadalafil. The supernatants were withdrawn after centrifugation (12000 $\mathrm{rpm}, 10 \mathrm{~min})$. Finally, the samples were filtrated with $0.22 \mu \mathrm{m}$ membrane filter and analyzed by HPLC using Shimadzu LC-20AT pump and Shimadzu SPD -M20A detector set at $285 \mathrm{~nm}$. A Platisil TM-ODS column $(4.6 \mathrm{~mm} \times 250 \mathrm{~mm}, 5 \mu \mathrm{m})$ was used. The mobile phase involved acetonitrile $-0.1 \%$ acetic acid aqueous solution mixture at $42: 58(\mathrm{~V} / \mathrm{V})$. The flow rate was $1.0 \mathrm{~mL} / \mathrm{min}$ at $35^{\circ} \mathrm{C}$. Aliquots of supernatants $(20 \mu \mathrm{L})$ were loaded 
on the HPLC. The linear regression equations in the plasma and lung were $\mathrm{A}=44.595 \mathrm{C}-745.3, \mathrm{r}=0.9998$ and $\mathrm{A}=37.946 \mathrm{C}+1081.3, \mathrm{r}=0.9998$, respectively. The results of methodology showed that this method fulfill the requirement of biological samples determination.

Another 54 healthy wistar rats were also randomLy divided into two groups. Control group and study group were treated with tadalafil solution and TDF-PLGA-MS suspension by intratracheal instillation, respectively. After stitching wounds, rats were killed at scheduled time $(0.5,2,4,8,24,48,96,144$ and $240 \mathrm{~h})$. The lungs, heart, liver, spleen and kidney of each rat were rapidly excised following blood collection, and immediately washed twice with normal saline $(0.9 \% \mathrm{NaCl})$. Subsequently, tissue samples were wiped with filter paper, precisely weighed and homogenized with $1.0 \mathrm{~mL}$ normal saline $(0.9 \% \mathrm{NaCl})$, except for liver $(2 \mathrm{~mL}) .0 .3 \mathrm{~mL}$ of acetonitrile was added to an aliquot $(0.2 \mathrm{~mL})$ of each sample and mixed for $4 \mathrm{~min}$ by vortex to extract tadalafil. The supernatants were withdrawn after centrifugation (12000 rpm, $10 \mathrm{~min}$ ) and analyzed by HPLC method described above.

\section{Statistical analysis}

Data were plotted as mean \pm standard deviation (S.D). The statistical analysis of significance was performed using unpaired Student's t-test. A P $<005$ indicated significant difference. An analysis of variance (ANOVA) test was also used if necessary. Pharmacokinetic parameters were obtained using DAS2.0 (drug and statistics for windows) program. A Re $>1$ indicated tissue targeting.

\section{RESULTS AND DISCUSSION}

\section{Results of the test of orthogonal design of VANH-Lip}

The EE and DL of nine formulations were determined using UV method described above and calculated by range analysis. The results were listed in Table II. Results indicated that the effect of (B) the concentration of PLGA was extremely significant, followed by (D) the volume ratio of aqueous to dispersed phase, (A) the ratio of drug to PLGA (w/w), (C) the volume ratio of lipid to aqueous phase, respectively. $\mathrm{k} 1, \mathrm{k} 2, \mathrm{k} 3$ are the weighted average value of three factors. The levels effects of each factor were as follows: (A) $1>3>2$, (B) $3>2>1$, (C) $1>2>3$, (D) $1>2>3$. Therefore, the optimal prescription was A1B3C1D1. Based on the actual situation, the ratio of drug to lipid was properly adjusted from 1:10 to $1: 8$ to save the material and improve DL. From the above, the optimal formulation and process were as follows: (A) $1: 8$, (B) $100 \mathrm{mg} / \mathrm{mL}$, (C) 1: 4, (D) $1: 5$.

The EE and DL of the TDF-PLGA-MS according to the optimal formulation and process were $(81.68 \pm 0.55) \%$ and $(8.52 \pm 0.06) \%$, respectively. The optimal formulation had a good feasibility and repeatability. Moreover, the EE and DL of microspheres were relatively high, which would be helpful to improve pharmaceutical and pharmacological effects in curing PAH.

TABLE II - Results of the test of orthogonal design of TDFPLGA-MS

\begin{tabular}{lccccc}
\hline No. & A & B & C & D & EE(\%) \\
\hline 1 & 1 & 1 & 1 & 1 & 71.11 \\
2 & 1 & 2 & 2 & 2 & 69.82 \\
3 & 1 & 3 & 3 & 3 & 76.51 \\
4 & 2 & 1 & 2 & 3 & 55.89 \\
5 & 2 & 2 & 3 & 1 & 69.42 \\
6 & 2 & 3 & 1 & 2 & 75.36 \\
7 & 3 & 1 & 3 & 2 & 56.40 \\
8 & 3 & 2 & 1 & 3 & 67.64 \\
9 & 3 & 3 & 2 & 1 & 81.93 \\
k1 & 72.480 & 61.133 & 71.370 & 74.153 & \\
k2 & 66.890 & 68.960 & 69.213 & 67.193 & \\
k3 & 68.657 & 77.933 & 67.443 & 66.680 & \\
R & 5.590 & 16.800 & 3.927 & 7.743 & \\
\hline F & &
\end{tabular}

Footer: A, B, C, D are (A) the ratio of drug to PLGA (w/w), (B) the concentration of PLGA (w/v), (C) the volume ratio of oil phase to aqueous phase, (D) the volume ratio of aqueous to dispersed phase, respectively. k1, k2, k3 are the weighted average value of four factors with three levels.

\section{Characterization of TDF-PLGA-MS}

\section{Physical and chemical property}

The appearance photographs of TDF-PLGA-MS freeze-dried powder were shown in Figure 2. The white freeze-dried powder appeared as full, fluffy and noncaking. The morphology of TDF-PLGA-MS was observed using SEM and microscope. As shown in Figure 3, the TDF-PLGA-MS were spherical particles and have no significant difference in morphology before and after lyophilization. Microspheres were still spherical after redissolving. The SEM image showed that most of the microspheres were smooth sphere with approximate size and uniform dispersion. No adhesion was found among the microspheres. 

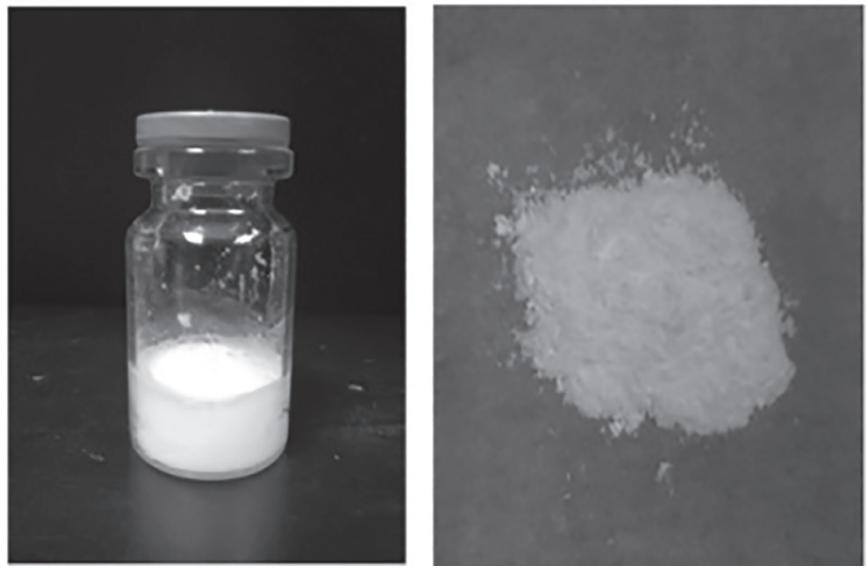

FIGURE 2 - The appearance of TDF-PLGA-MS.

The size of TDF-PLGA-MS was unformLy distributed as shown in Figure 4. The particle sizes of freshprepared and lyophilized microspheres from Malvern Laser Particle Size Analyzer 2000 were $(10.04 \pm 0.09) \mu \mathrm{m}$ and $(10.29 \pm 0.25) \mu \mathrm{m}$, which was consistent with the results of SEM. No significant difference in particle size was found between fresh-prepared and lyophilized microspheres. The D90 value was about $20 \mu \mathrm{m}$, which indicated a relatively narrow distribution. The $\mathrm{pH}$ value of TDF-PLGA-MS was
$6.95 \pm 0.05$, meeting the physiological $\mathrm{pH}$ in the body. Collectively, the TDF-PLGA-MS prepared in this study was suitable for pulmonary administration.

\section{DSC}

The DSC analysis were performed on tadalafil raw material, blank microspheres, the physical mixture of tadalafil and blank microspheres, and freeze-dried TDF-PLGA-MS to inspect the melting, crystallization behavior and polymorphism. The DSC thermograms were shown in the Figure 5 . The endothermic peak at $50{ }^{\circ} \mathrm{C}$ is the melting point of PLGA. The DSC results indicated that tadalafil had a distinct endothermic peak at $305^{\circ} \mathrm{C}$ and an exothermic peak at $376{ }^{\circ} \mathrm{C}$. In addition, there were similar peaks to tadalafil except endothermic peak of PLGA at $315{ }^{\circ} \mathrm{C}$ in the physical mixture, which may reveal that tadalafil was in crystalline state in the physical mixture. However, no peaks of tadalafil were observed in the DSC curve of tadalafil microspheres, which indicated that tadalafil was not in crystalline state but dispersed in microspheres.

\section{Micromeritic characteristics}

The micromeritic characteristics contribute to the

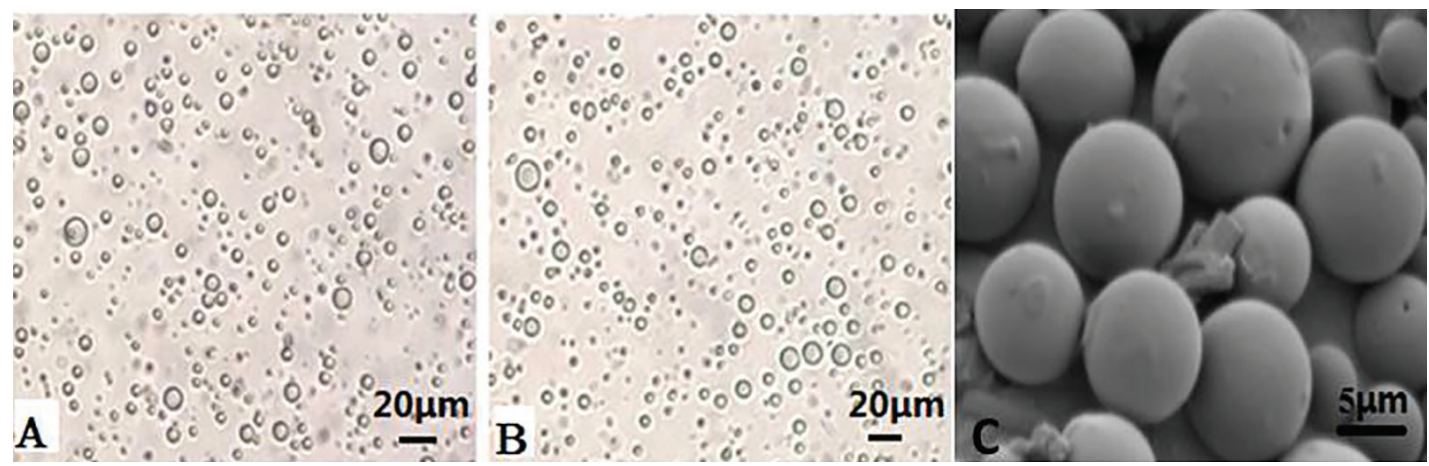

FIGURE 3 - Microscopy photograph of TDF loaded PLGA microspheres: (A) fresh-prepared; (B) suspension of freeze-dried powder; (C) the SEM of freeze-dried powder.
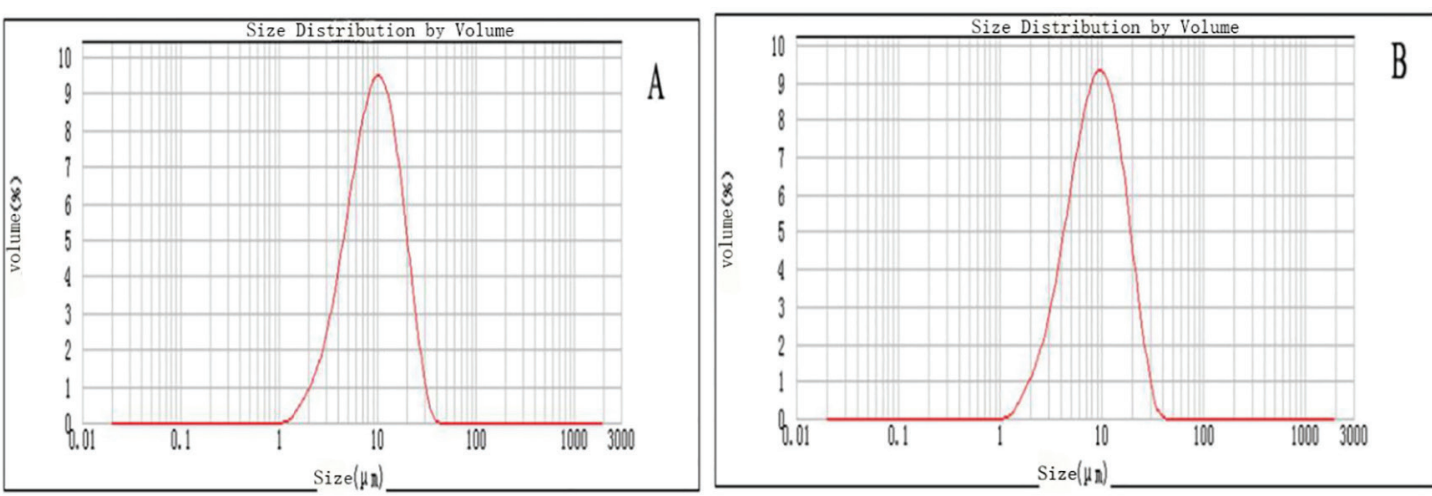

FIGURE 4 - Size distribution of TDF loaded PLGA microspheres: (A) Microspheres after freeze-drying; (B) Microspheres before freeze-drying. 


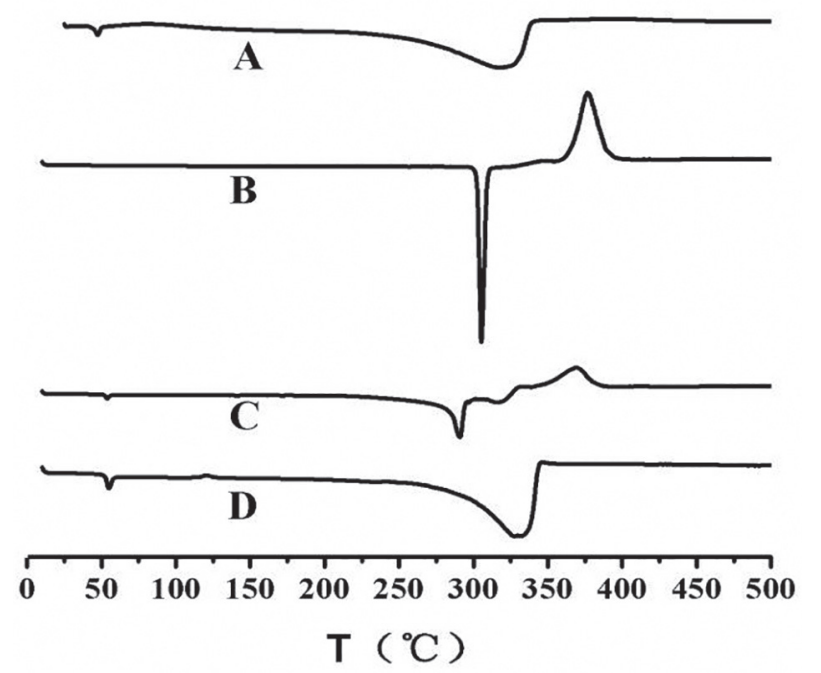

FIGURE 5 - The results of DSC of PLGA microspheres:(A) blank microspheres; (B) tadalafil; (C) mixture; (D) tadalafil loaded microspheres).

quality and therapeutic effect of inhalation, involving moisture content, angle of repose, bulk density, particle size aerodynamics, emptying rate, atomization characteristics, etc. The results in Table III showed that TDF-PLGA-MS had a low moisture content, which was conducive to the stability, atomization, and emptying of microspheres powder. The average bulk density was less than $190 \mathrm{mg} / \mathrm{mL}$, which indicated that the microspheres powder was fluffy and easily dispersed. The average angle of repose was less than 38 degrees, indicating that the microspheres powder had a relatively good flowability. The flowability of microspheres powder still need to be improved with additament. The particles with aerodynamic diameter ranging from 1 to $5 \mu \mathrm{m}$ can readily accumulate in the deep region of lung (Kandasamy, Chandrasekaran, 2013; Varshosaz et al., 2017). The aerodynamic diameter of tadalafil microspheres prepared in this study was $3.92 \mu \mathrm{m}$, so the microspheres powder was easy to accumulate in lung. The atomization characteristics determine whether the powder quickly disperses into alveoli by atomization apparatus. The tadalafil microspheres powder had a very easy atomization in experiment, so the atomization level accorded with " 3 ". The emptying rate was $95.41 \%$, which revealed that the TDF-PLGA-MS could be fully emptied. From the above, the TDF-PLGA-MS prepared in this study can meet the requirements of inhalation for pulmonary administration.

\section{Drug release in vitro}

The in vitro release profile of TDF-PLGA-MS was shown in Figure 6. Results indicated that more than
TABLE III - Micromeritic of TDF-PLGA-MS (n=3)

\begin{tabular}{cc}
\hline Sample & Average \pm SD \\
\hline Moisture content $(\%)$ & $1.99 \pm 0.23$ \\
Bulk density $(\mathrm{mg} / \mathrm{mL})$ & $58.64 \pm 2.06$ \\
Repose angle $\left({ }^{\circ}\right)$ & $35.90 \pm 2.05$ \\
Aaerodynamic diameter $(\mu \mathrm{m})$ & $3.92 \pm 0.06$ \\
Atomized grades & " 3 " \\
Emptying ratio $(\%)$ & $95.41 \pm 1.22$ \\
\hline
\end{tabular}

$80 \%$ of the drug released from tadalafil solution within $4 \mathrm{~h}$. The cumulative release reached $98.72 \%$ within $8 \mathrm{~h}$. The release of tadalafil $(<100 \%)$ from solution was in accordance with the Weibull and Ritger-Peppas model at the same time and could be expressed using the following equations, respectively: $\ln (1 /(1-\mathrm{Q} / 100)=0.81 \ln t-0.3981$ and $\ln Q=0.3835 \ln t+3.8577,(\mathrm{r}=0.9911)$. The equations showed that the release of tadalafil from solution accorded with Fick's diffusion mechanism. Compared with tadalafil solution, only $19.32 \%$ of the drug released from TDF-PLGA-MS in $4 \mathrm{~h}$. The cumulative release reached $30.48 \%$ in $8 \mathrm{~h}$. The cumulative release of tadalafil from microspheres was $84.06 \%$ within $10 \mathrm{~d}$, indicating a prolonged release of tadalafil from TDF-PLGA-MS as compared to the tadalafil solution. The release of tadalafil from microspheres $(<85 \%)$ was consistent with the Weibull model and could be expressed using the following equation: $\ln (1 /(1-\mathrm{Q} / 100)=0.5538 \ln t-2.3209, \mathrm{r}=0.9968$. The equations showed that the release of tadalafil from microspheres accorded with Fick's diffusion mechanism, too. In addition, somewhat burst release was found in the release behavior of TDF-PLGA-MS, which was in favour of quickly reaching effective blood concentrations and improving therapeutic effect (Acharya, Park, 2006).

\section{Pharmacokinetics and tissue distribution}

\section{Pharmacokinetics}

The blood concentration-time curves of tadalafil in rats after intratracheal instillation were shown in Figure 7. Data suggested that the blood concentration increased rapidly after intratracheal instillation of tadalafil solution. The concentration of tadalafil in blood reached $724.17 \mathrm{ng} / \mathrm{mL}$ in $0.5 \mathrm{~h}$. The main reason was that there were abundant blood capillaries in lung with large surface area which were good for the rapid absorption of drug (Ryan et al., 2013). However, the concentration of tadalafil from TDF-PLGA-MS was only $65.82 \mathrm{ng} / \mathrm{mL}$ within $0.5 \mathrm{~h}$ after instillation. Then the blood concentration slowly went up with the release of drug in the microspheres. A decrease could be seen when the rate of release was lower 


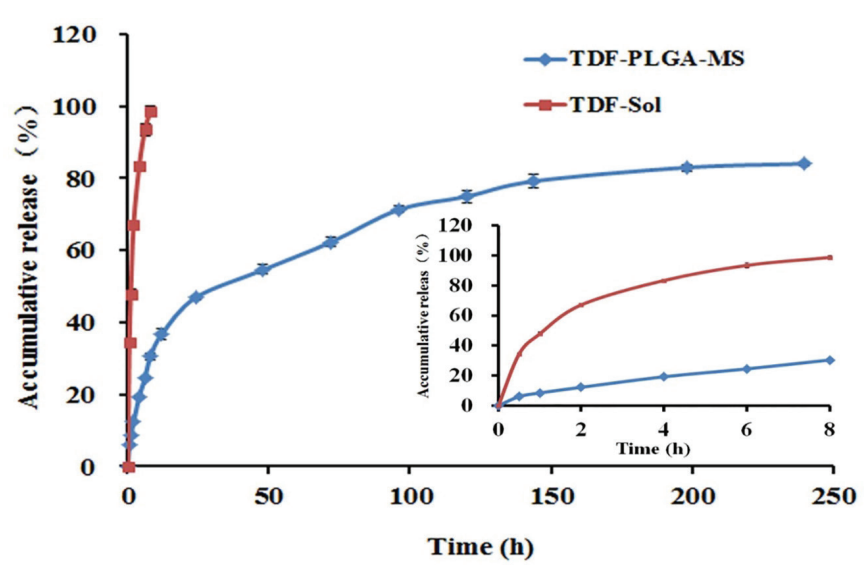

FIGURE 6 - In vitro release profile of TDF from TDF-PLGAMS and TDF-Sol.

than that of elimination in $12 \mathrm{~h}$. In comparison with the tadalafil solution, the tadalafil microspheres had little leakage in blood circulation, which was helpful to improve the utilization of drugs and reduce the systematic adverse reactions.

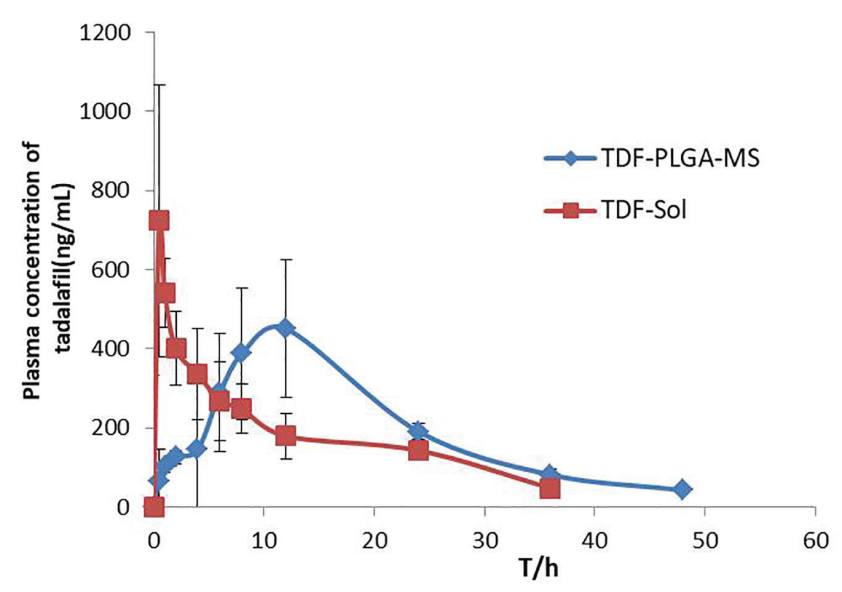

FIGURE 7 - Mean drug concentration-time curves of TDF in plasma after intratracheal instillation of TDF -Sol and TDFPLGA-MS.

\section{Tissue distribution}

The tissue distributions of tadalafil from solution and microspheres after intratracheal instillation were shown in Figure 8. Remarkably, the drug distribution in different tissues was also different between the tadalafil solution and the tadalafil microspheres. Briefly, the concentration of drug from microspheres in each tissue clearly decreased compared with solution group, which proved that microspheres pulmonary administration could reduce the drug distribution in other tissues except lung. The drug concentration versus time curve in lung was shown in Figure 9. The tadalafil concentration in lung dramatically decreased after intratracheal instillation of
A
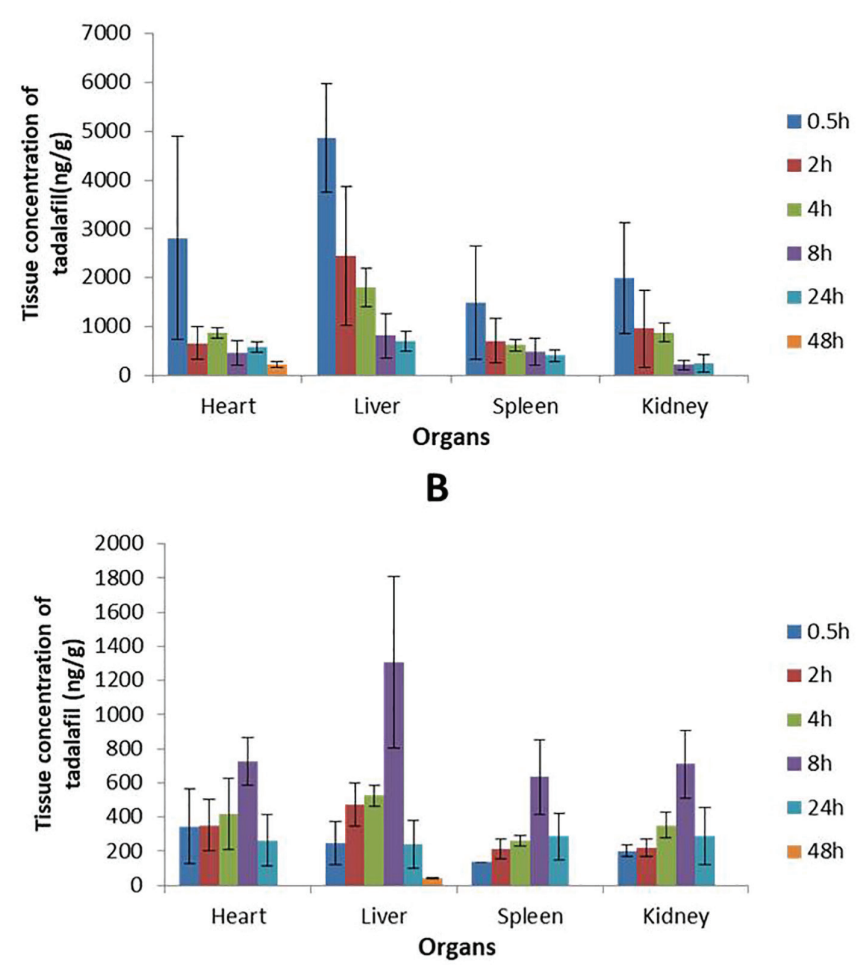

FIGURE 8 - Tissue distribution at different time points in rat after intratracheal instillation: (A) TDF-Sol; (B) TDF - PLGA-MS.

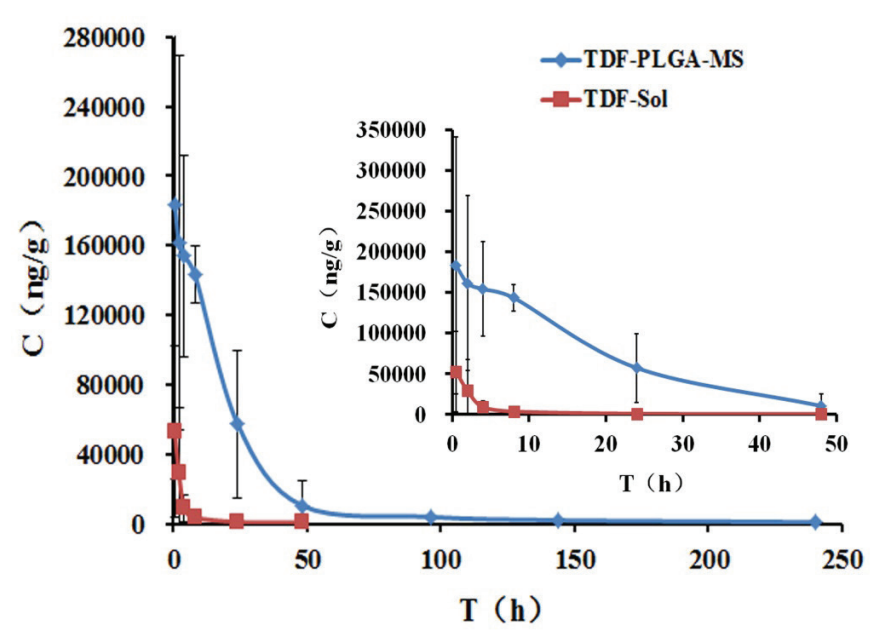

FIGURE 9 - Mean residual concentration-time curves of TDF in lung after intratracheal instillation of TDF -Sol and TDFPLGA-MS.

tadalafil solution. The drug concentration in $0.5 \mathrm{~h}$ and $48 \mathrm{~h}$ were $52732.34 \mathrm{ng} / \mathrm{g}$ and $481.86 \mathrm{ng} / \mathrm{g}$, respectively. However, after instillation of TDF-PLGA-MS, the drug concentrations in $0.5 \mathrm{~h}$ and $48 \mathrm{~h}$ were $183458.83 \mathrm{ng} / \mathrm{g}$ and $10428.55 \mathrm{ng} / \mathrm{g}$, which were 3.5 and 21.6 times those of the solution group, respectively. The concentriation of tadalafil from microspheres in lung still reached $866.69 \mathrm{ng} / \mathrm{g}$ after $10 \mathrm{~d}$ which was higher than that from tadalafil solution 
in $48 \mathrm{~h}$. It indicates that the TDF-PLGA-MS prepared in this study can slowly release the drug for $10 \mathrm{~d}$ in the lung. So tadalafil microspheres are with good sustained -release effect.

The pharmacokinetic parameters were calculated by DAS 2.0 software and shown in Table IV. The pharmacokinetic in the plasma and lung were all in accordance with two-compartment model. After intratracheal instillation of TDF-PLGA-MS, the $t_{1 / 2} \alpha$ and $t_{1 / 2} \beta$ were $10.128 \mathrm{~h}$ and $69.135 \mathrm{~h}$, which were 7.22 and 3.10 times those of the solution group, respectively. The $\mathrm{MRT}_{0-\infty}$ of $28.244 \mathrm{~h}$ was 3.96 times that of solution group. The $\mathrm{C}_{\max }$ and $\mathrm{AUC}_{0-\infty}$ in lung were $183.459 \mu \mathrm{g} / \mathrm{g}$ and $4060.097 \mathrm{mg} / \mathrm{L} * \mathrm{~h}$, which were 3.48 and 16.36 times those of solution group, respectively. From the above, the TDF-PLGA-MS for pulmonary administration can clearly prolong the residence time of tadalafil in lung to maintain a relatively high concentration for a long time, which contributes to reducing the leakage in blood circulation and administration dosage. Thereby, the treatment effect for PAH will be improved and systemic side effects will also be reduced at the same time.

In this study, the Re was used to evaluate the targeting characteristics of TDF-PLGA-MS. The Re of

TABLE IV - The pharmacokinetic parameters in lung of TDF after intratracheal instillation of TDF -Sol and TDF-PLGA-MS

\begin{tabular}{lcc}
\hline Parameters & TDF-PLGA-MS & TDF-Sol \\
\hline $\mathrm{t}_{1 / 2 \alpha}(\mathrm{h})$ & $10.128 \pm 0.598$ & $1.402 \pm 0.221$ \\
$\mathrm{t}_{1 / 2 \beta}(\mathrm{h})$ & $69.315 \pm 0.991$ & $22.277 \pm 0.397$ \\
$\mathrm{~V}_{1}(\mathrm{~L} / \mathrm{kg})$ & $0.049 \pm 0.007$ & $0.153 \pm 0.018$ \\
$\mathrm{CL}(\mathrm{L} / \mathrm{h} / \mathrm{kg})$ & $0.002 \pm 0.001$ & $0.040 \pm 0.007$ \\
$\mathrm{AUC}_{0-\infty}(\mathrm{mg} / \mathrm{L} * \mathrm{~h})$ & $4060.097 \pm 1.995$ & $248.199 \pm 0.897$ \\
$\mathrm{MRT}_{0-\infty}(\mathrm{h})$ & $28.244 \pm 0.528$ & $7.140 \pm 0.108$ \\
$\mathrm{~T}_{\max }(\mathrm{h})$ & $11.000 \pm 0.193$ & $0.500 \pm 0.098$ \\
$\mathrm{C}_{\max }(\mu \mathrm{g} / \mathrm{g})$ & $183.459 \pm 0.894$ & $52.732 \pm 0.627$ \\
\hline
\end{tabular}

TDF-PLGA-MS after intratracheal instillation was listed in Table V. The Re $>1$ indicated the tissue targeting. The Re in heart, spleen, liver and kidneys were $0.354,0.451,0.451$ and 0.699 , respectively. Therefore, no or low targeting characteristics were found in these tissues. The Re in these tissues were all less than 1, which was helpful to reduce the potential toxicity especially in liver and kidney. However, the Re in lungs was 16.358 , which indicated the great tissue targeting characteristics. To sum up, the TDF-PLGA-MS can reduce the drug distribution in nontarget organ and greatly increase the drug concentration in lungs to improve the therapeutic effect of tadalafil for PAH.

\section{CONCLUSIONS AND OUTLOOK}

In this study, the TDF-PLGA-MS were prepared using modified emulsion-solvent evaporation method to be applied to pulmonary delivery. The particle size of microspheres could be easily controlled (Emami et al., 2009). The tadalafil microspheres prepared in this study can meet the requirements of pulmonary inhalation. The sustained release effect of tadalafil microspheres in lungs can last 10 days after pulmonary administration. The pharmacokinetics results show little leakage of tadalafil from microspheres is found in blood circulation. Moreover, tadalafil from microspheres can be retained in lungs for a long time and slowly release to reduce the adverse reactions and improve the therapeutic effect for PAH. Experimental results of tissues distribution show that the drug concentration in heart, liver, spleen and kidney are reduced but increased in lungs. So the tadalafil microspheres can reduce the drug distribution in non-target organs and greatly increase the drug retention in lungs to improve the therapeutic effect of tadalafil for PAH. At the same time, the potential toxicity especially in liver and kidney will be reduced.

Although the dose for treating PAH is greater than that for male erectile dysfunction, with a longacting release function of microspheres, the drug from

TABLE V - Tissue targeting parameters of TDF-PLGA-MS after intratracheal instillation in rat

\begin{tabular}{lccc}
\hline \multirow{2}{*}{ Tissues } & \multicolumn{2}{c}{ AUC } & \multirow{2}{*}{ Re } \\
\cline { 2 - 3 } & TDF-PLGA-MS & TDF-Sol & 0.367 \\
Heart & $12101.169 \pm 2.512$ & $33005.105 \pm 2.578$ & 0.442 \\
Liver & $16201.364 \pm 1.238$ & $36635.684 \pm 2.689$ & 0.451 \\
Spleen & $9285.362 \pm 0.859$ & $20591.025 \pm 1.859$ & 0.699 \\
Kidney & $10501.217 \pm 3.198$ & $15025.624 \pm 0.892$ & 16.358 \\
Lung & $4060096.878 \pm 5.589$ & $248198.762 \pm 3.127$ & \\
\hline
\end{tabular}

Footer: Re, namely relative uptake rate. 
microspheres slowly release into the lung. Only an aliquot of tadalafil does leak into the systemic circulation. Therefore, it is less likely to lead to male erection. In summary, the TDF-PLGA-MS inhalant is a sustained release formulation which can be used for pulmonary delivery and of great significance for future clinical application.

\section{ACKNOWLEDGMENTS}

The authors would like to express gratitude to the school of pharmacy in Shandong University for providing the required facilities to finish the research. The authors want to thank classmates in the same laboratory for their assistance. In addition, the authors thank Miao Lei for the revision of the whole manuscript carefully.

\section{REFERENCES}

Acharya G, Park K. Mechanisms of controlled drug release from drug-eluting stents. Adv Drug Deliv Rev. 2006;58(3):387-401.

Anderson JM, Shive MS. Biodegradation and biocompatibility of PLA and PLGA microspheres. Adv Drug Deliver Rev. 2012;64:72-82.

Archer S L, Michelakis E D. Phosphodiesterase type 5 inhibitors for pulmonary arterial hypertension. New Engl J Med. 2009;361(19):1864-1871.

Azarmi S, Roa W H, Löbenberg R. Targeted delivery of nanoparticles for the treatment of lung diseases. Adv Drug Deliver Rev. 2008;60(8):863-875.

Barst RJ, McGoon M, Torbicki A, Sitbon O, Krowka MJ, Olschewski H, Gaine S. Diagnosis and differential assessment of pulmonary arterial hypertension. J Am Coll Cardiol. 2004;43(12 Suppl 1):S40-S47.

Carson CC, Rajfer J, Eardley I, Carrier S, Denne JS, Walker DJ, Shen W, Cordell WH. The efficacy and safety of tadalafil: an update. BJU Int, 2004;93(9):1276-1281.

Carvalho TC, Peters JI, Williams RO. Influence of particle size on regional lung deposition-what evidence is there? Int $\mathrm{J}$ Pharmaceut. 2011;406(1):1-10.

Chin KM, Rubin LJ. Pulmonary arterial hypertensionc. J Am Coll Cardiol. 2008;51(16):1527-1538.
Cook RO, Pannu RK, Kellaway IW. Novel sustained release microspheres for pulmonary drug delivery. J Control Release. 2005;104(1):79-90.

Dunne M, Corrigan OI, Ramtoola Z. Influence of particle size and dissolution conditions on the degradation properties of polylactide-co-glycolide particles. Biomaterials. 2000;21(16):1659-1668.

Ely L, Roa W, Finlay WH, Löbenberg R. Effervescent dry powder for respiratory drug delivery. Eur J Pharm Biopharm. 2007;65(3):346-353.

Emami J, Hamishehkar H, Najafabadi AR, Gilani K, Minaiyan M, Mahdavi H, et al. Particle size design of PLGA microspheres for potential pulmonary drug delivery using response surface methodology. J Microencapsul. 2009;26(1):1-8.

Fenstad ER, Le RJ, Sinak LJ, Maradit-Kremers H, Ammash NM, Ayalew AM, et al. Pericardial effusions in pulmonary arterial hypertension: characteristics, prognosis, and role of drainage. Chest. 2013;144(5):1530-1538.

Freiberg S, Zhu XX. Polymer microspheres for controlled drug release. Int J Pharmaceut. 2004;282(1):1-18.

Galiè N, Humbert M, Vachiery JL, Gibbs S, Lang I, Torbicki A, et al. ESC/ERS Guidelines for the diagnosis and treatment of pulmonary hypertension: The Joint Task Force for the Diagnosis and Treatment of Pulmonary Hypertension of the European Society of Cardiology (ESC) and the European Respiratory Society (ERS). Endorsed by: Association for European Paediatric and Congenital Cardiology (AEPC), International Society for Heart and Lung Transplantation (ISHLT). Eur Heart J. 2015;46(4):903-75.

Galiè N, Brundage BH, Ghofrani HA, Oudiz RJ, Simonneau G, Safdar Z, et al. Tadalafil therapy for pulmonary arterial hypertension. Circulation. 2009;119(22):2894-2903.

Gomberg-Maitland M, Olschewski H. Prostacyclin therapies for the treatment of pulmonary arterial hypertension. Eur Respir J. 2008;31(4):891-901.

Hardy JG, Chadwick TS. Sustained release drug delivery to the lungs. Clin Pharmacokinet. 2000;39(1):1-4.

Hoeper MM, Bogaard HJ, Condliffe R, et al. Definitions and diagnosis of pulmonary hypertension. Turk Kardiyoloji Dernegi arsivi: Turk Kardiyoloji Derneginin yayin organidir. 2014;42:55-66. 
Kandasamy R, Chandrasekaran K. Sustained release aerosol for pulmonary drug delivery system: a review. Int J Pharm Pharm Sci. 2013;5(3):126-130.

Kleinstreuer C, Zhang Z, Donohue JF. Targeted drug-aerosol delivery in the human respiratory system. Annu Rev Biomed Eng. 2008;10:195-220.

Kloner RA, Mitchell M, Emmick JT. Cardiovascular effects of tadalafil in patients on common antihypertensive therapies. Am J Cardiol. 2003;92(9):47-57.

Lakio S, Morton DAV, Ralph AP, Lambert P. Optimizing aerosolization of a high-dose L-arginine powder for pulmonary delivery. Asian J Pharm Sci. 2015;10(6):528-540.

Lam PY, Lam PS, Sokhansanj S, Bi XT, Jim Lim C, Melin S. Effects of pelletization conditions on breaking strength and dimensional stability of Douglas fir pellet. Fuel. 2014;117(Part B):1085-1092.

Oudiz RJ, Brundage BH, Galiè N, Ghofrani HA, Simonneau G, Botros FT, et al. Tadalafil for the treatment of pulmonary arterial hypertension: a double-blind 52-week uncontrolled extension study. J Am Coll Cardiol. 2012;60(8):768-774.

Park TG. Degradation of poly (lactic-co-glycolic acid) microspheres: effect of copolymer composition. Biomaterials. 1995;16(15):1123-1130.

Rhodes CJ, Davidson A, Gibbs JSR, Wharton J, Wilkins MR. Therapeutic targets in pulmonary arterial hypertension. Pharmacol Ther. 2009;121(1):69-88.

Ryan GM, Kaminskas LM, Kelly BD, Owen DJ, McIntosh MP, Porter CJ. Pulmonary administration of PEGylated polylysine dendrimers: absorption from the lung versus retention within the lung is highly size-dependent. Mol Pharmaceut. 2013;10(8):2986-2995.
Salma I, Füri P, Németh Z, Balásházy I, Hofmann W, Farkas A. Lung burden and deposition distribution of inhaled atmospheric urban ultrafine particles as the first step in their health risk assessment. Atmosph Environ. 2015;104:39-49.

Sham JOH, Zhang Y, Finlay WH, Roa WH, Löbenberg R. Formulation and characterization of spray-dried powders containing nanoparticles for aerosol delivery to the lung. Int $\mathrm{J}$ Pharmaceut. 2004;269(2):457-467.

Varshosaz J, Taymouri S, Hamishehkar H, Vatankhah R, Yaghubi S. Development of dry powder inhaler containing tadalafilloaded PLGA nanoparticles. Res Pharm Sci. 2017;12(3):222-32.

Wang HC, John W. Particle density correction for the aerodynamic particle sizer. Aerosol Sci Tech. 1987;6(2):191198.

Watts AB, McConville JT, Williams III RO. Current therapies and technological advances in aqueous aerosol drug delivery. Drug Dev Ind Pharm. 2008;34(9):913-922.

Wong ACY. Use of angle of repose and bulk densities for powder characterization and the prediction of minimum fluidization and minimum bubbling velocities. Chem Eng Sci. 2002;57(14):2635-2640.

Zeng XM, Martin GP, Marriott C. The controlled delivery of drugs to the lung. Int J Pharmaceut. 1995;124(2):149-164.

Received for publication on $06^{\text {th }}$ September 2017 Accepted for publication on $03^{\text {th }}$ August 2018 